\title{
COMPATIBLE AND INCOMPATIBLE POLLINATION AND THE SENESCENCE AND OVARY GROWTH OF DENDROBIUM FLOWERS
}

\author{
KANJANA LUANGSUWALAI ${ }^{1}$, ROBERT E. PAULL ${ }^{2}$, \\ and SAICHOL KETSA $1,3,4, *$
}

\footnotetext{
${ }^{1}$ Agriculture Program, Faculty of Science and Technology, Bansomdejchaopraya Rajabhat University, Thonburi, Bangkok 10600, Thailand

2 Department of Tropical Plant and Soil Sciences, University of Hawaii at Manoa, Honolulu, HI 96822-2279, USA

${ }^{3}$ Department of Horticulture, Faculty of Agriculture, Kasetsart University, Chatuchak, Bangkok 10900, Thailand

${ }^{4}$ Academy of Science, The Royal Institute, Dusit, Bangkok 10300, Thailand

*Corresponding author: agrsck@ku.ac.th
}

\begin{abstract}
The pollinia from five cultivars of Dendrobium ('Miss Teen', 'Karen', 'Sakura', 'Willie', and 'Pompadour') were placed on the stigma of open flowers of Dendrobium 'Miss Teen' (or 'Kenny'). The ethylene production and post-pollination development of cross-pollinated flowers were monitored. The pollinated flowers showed two different development patterns depending upon pollination compatibility. The first group, which was pollinated with incompatible pollen from flowers of 'Karen' and 'Miss Teen', did not exhibit post-pollination symptoms and ovary growth. The second group, which was pollinated with compatible pollen from flowers of 'Pompadour', 'Sakura' and 'Willie', showed premature perianth senescence and induced ovary growth within a day. Compatible pollination of 'Miss Teen' flowers resulted in an immediate burst in the production of ethylene and a rapid ovary growth followed by an increase in pollen tube length. In contrast when 'Miss Teen' flowers were self-pollinated or pollinated with 'Karen' pollinia, these changes did not occur. In the pollinia of 'Pompadour', 'Sakura' and 'Willie' there were higher levels of auxin and 1-aminocyclopropane-1-carboxylic acicd (ACC) than in those of 'Miss Teen' and 'Karen'. Compatible pollination also resulted in higher ACC synthase and ACC oxidase activities within $12 \mathrm{~h}$ after pollination than after pollination with incompatible pollen. There was a low level of ACC oxidase activity in non-pollinated flowers and a higher ACC oxidase activity in the column plus pedicel than petal plus sepal and lip.
\end{abstract}

Keywords: ethylene production, ovary growth, auxin, 1-aminocyclopropane-1-carboxylic acid, senescence

\section{Introduction}

Pollination is important for the successful sexual reproduction of flowering plants. Compatibility of the pollen is crucial for the production of seeds of newly inbred orchids or rare species in commercial propagation $(\mathrm{Ag}$ garwal et al. 2012; Cevdet and Sebnem 2012; Damon et al. 2012) In addition to ovary growth and seed development, pollination induces early senescence of the flowers of many species of carnation, cyclamen, petunia, tobacco, and orchids (Herrero and Dickinson 1980; Halevy et al. 1984; Hill et al. 1987; Stead 1992; Halevy 1995a; Porat et al. 1995; Porat et al. 1998; Ketsa and Rugkong 2000; Xu and Hanson 2000; Ketsa et al. 2001). Generally, pollination can be divided into three stages: 1) contact of pollen with the stigma, 2) growth of pollen tubes into the style and 3) fertilization of ovules (Halevy 1995b).

The early senescence of the perianth following pollination is accompanied by an increase in the production of ethylene (Woodson and Lawton 1988; Porat et al. 1995; Woltering et al. 1995). The gaseous hormone ethylene is produced by all parts of higher plants, with the rate of production dependent on tissue type and the stage of development. Ethylene biosynthesis is most active in meristematic and nodal regions and also increases during leaf abscission, flower senescence and the ripening of fruit (Have and Woltering 1997). Auxin, wounding and physiological stress, associated with flooding, chilling, disease, high temperature or drought, can induce the biosynthesis of ethylene (Woodson et al. 1992). The biosynthetic pathway resulting in the production of ethylene by pollinated flowers is the same as in ripening fruit and wounded tissue. In the first step, methionine is converted to SAM (S-adenosyl methionine) by SAM synthase, which is then converted to ACC (1-aminocyclopropane-1-carboxylic acid) by ACC synthase, which is oxidized to ethylene by ACC oxidase (Yang and Hoffman 1984; Taiz and Zeiger 1998).

Self-incompatibility (SI) is a reproductive strategy of flowering plants that enables the pistil to reject genetically related pollen. In contrast, pollen from other plants is accepted by the pistil and the pollen tube grows down through the style to reach the ovary where fertilization occurs (McCubbin and Kao 2000). SI is found in many species of plants, such as petunia (Herrero and Dickinson 1979) where compatible pollination leads to rapid senescence. Petunia flowers pollinated with incompatible pollen last almost as long as non-pollinated flowers. After pollination compatible pollen contains a higher content of ACC and induces higher levels of ethylene production than incompatible pollen (Singh et al. 1992). Baker et al. (1997) also report that in Theobroma cacao L., IAA concentrations increase in compatibly pollinated flowers but remain stable in incompatibly pollinated flowers. Although SI occurs in Dendrobium the physiological changes following pollination with compatible and non-compatible pollen, however, has not been reported. 
Dendrobium is a very large genus of orchids established by Olof Swartz in 1799 and today contains about 1,200 species. The genus occurs in diverse habitats throughout much of south, east and southeast Asia, including the Philippines, Borneo, Australia, New Guinea, Solomon Islands and New Zealand. Dendrobium orchids are the most important cut-flowers exported by Thailand. To meet commercial needs, new cultivars of Dendrobium orchids are developed by amateur and scientific breeders. However, SI is frequently encountered when attempting self- and cross-pollination. In a preliminary study we have shown that cut flowers of Dendrobium kept in test tubes containing sugar and an antimicrobial compound can be pollinated successfully and develop pods with seeds that germinate to produce plantlets. This method is suitable for use in breeding programs as it enables one to cross many plants in conditions where it is possible to control the temperature, relative humidity and light.

Here, our results of controlled pollination experiments with cut flowers of Dendrobium are reported. Pollination by compatible pollen is followed by early perianth senescence and ovary growth whereas that by incompatible pollen by delayed senescence and no ovary growth. The objectives of this study were: (i) to compare the physiological changes and ethylene production following compatible and incompatible pollination of cut flowers of Dendrobium, and (ii) to determine the ethylene production by pollinated flowers of Dendrobium following pollination by compatible and incompatible pollen.

\section{Materials and methods}

Inflorescences of Dendrobium 'Miss Teen' or 'Kenny', Dendrobium 'Sakura, Dendrobium 'Pompadour', Dendrobium 'Willie' and Dendrobium 'Karen' were purchased from a suburban Bangkok grower. The inflorescences with five to six open flowers and three to five flower buds were harvested in the morning and returned to the laboratory within $2 \mathrm{~h}$ of harvest. The peduncle and attached buds were cut off and only the first five open flowers were used. The peduncle of each inflorescence was cut at an angle, $12 \mathrm{~cm}$ from the base of the first open flower and the cut end inserted into a $15-\mathrm{ml}$ centrifuge tube containing $10 \mathrm{ml}$ of distilled water. These inflorescences were kept under natural light (about $15 \mu \mathrm{mol} \mathrm{m} \mathrm{m}^{-1} \mathrm{~s}^{-1}$ ), ambient temperature (average $25^{\circ} \mathrm{C}$ ) and relative humidity (average $70 \% \mathrm{RH}$ ) conditions during the period of the study.

\section{Identification of compatible and incompatible pollinia}

Open flowers of Dendrobium 'Miss Teen' were used as the female parent. The open flowers were hand pollinated by placing the pollinia from 5 cultivars of Dendrobium, namely 'Miss Teen', 'Karen, 'Pompadour', 'Sakura' and 'Willie', onto the stigma without removing the anther cap and pollinia. There were 25 replicates of each experiment (one flower/replication) and six treatments as follows:

1. Non-pollinated flowers of Dendrobium 'Miss Teen' as the control

2. Dendrobium 'Miss Teen' $\times$ Dendrobium 'Miss Teen'

3. Dendrobium 'Miss Teen' $\times$ Dendrobium 'Karen'

4. Dendrobium 'Miss Teen' $\times$ Dendrobium 'Pompadour'

5. Dendrobium 'Miss Teen' $\times$ Dendrobium 'Sakura'

6. Dendrobium 'Miss Teen' $\times$ Dendrobium 'Willie'

In treatments 2 and 3, pollination was incompatible, whereas in treatments 4, 5 and 6 it was compatible. Post-pollination developmental events were observed and recorded as follows:

1. Symptoms of senescence were noted. The changes in the pollinated flowers and the time to onset of senescence indicated by epinasty (the pollinated flowers turn upside down), drooping, venation, fading, lip yellowing and petal senescence of individual open flowers were recorded daily.

2. Distance between lip and peduncle in $\mathrm{cm}$ (Ketsa and Rugkong 1999).

3. The ovary diameter $(\mathrm{mm})$ was determined at the proximal end, using a caliper.

4. Ethylene production.

To measure ethylene production, the cut ends of two inflorescences bearing only 4 open flowers from the bottom were weighed and the cut ends inserted into centrifuge tubes containing $10 \mathrm{ml}$ of distilled water and placed into an empty, air-tight 41 bottle with gas sampling ports. At various intervals the bottles were sealed for $2 \mathrm{~h}$ and a $1 \mathrm{ml}$ gas sample was withdrawn from the headspace for ethylene determination using a gas chromatograph equipped with a flame ionization detector (Shimadzu GC-14A). After each determination, all the inflorescences were removed from the bottles.

\section{Indoleacetic acid (IAA) and 1-aminocyclopropane-1-carboxylic acid (ACC) content of pollinia}

To analyze IAA and ACC content, incompatible and compatible pollinia were collected from open flowers for extraction and analysis. Pollinia of 'Karen' were incompatible, while those of 'Sakura' were compatible. There were three replicates for each cultivar.

ACC was extracted and analyzed following the method of Lizada and Yang (1979) modified by Hoffman and Yang (1982). Pollinia were weighed (0.03 g) and ground in $5 \mathrm{ml}$ of $9 \%$ trichloroacetic acid (TCA) using a mortar and pestle. ACC content was measured in terms of the oxidative release of ethylene, as described by Lizada and Yang (1979) Ethylene levels were measured in $1.0 \mathrm{ml}$ of the headspace after $5 \mathrm{~min}$. To measure the efficiency of conversion of ACC to ethylene in the extracts, $0.5 \mathrm{ml}$ of the extract was spiked with $0.4 \mathrm{nmol}$ of ACC to 
Table 1 Time to petal senescence of non-pollinated flowers of Dendrobium 'Miss Teen' and those pollinated with pollinia from five other cultivars.

\begin{tabular}{|c|c|c|c|c|c|c|}
\hline Treatment & Epinasty & Droop & Venation & Lip yellowing & Fading & Browning \\
\hline $\begin{array}{l}\text { 'Miss Teen' (No pollination) } \\
\text { 'Miss Teen' } \times \text { 'Miss Teen' } \\
\text { 'Miss Teen' } \times \text { 'Karen' } \\
\text { 'Miss Teen' } \times \text { 'Pompadour' } \\
\text { 'Miss Teen' } \times \text { 'Willie' } \\
\text { 'Miss Teen' } \times \text { 'Sakura' }\end{array}$ & $\begin{array}{r}>15.6^{\mathrm{a}} \\
>12.8^{\mathrm{b}} \\
>9.8^{\mathrm{c}} \\
1.1^{\mathrm{d}} \\
1.1^{\mathrm{d}} \\
1.1^{\mathrm{d}}\end{array}$ & $\begin{aligned}> & 16.2^{\mathrm{a}} \\
> & 14.7^{\mathrm{b}} \\
> & 11.2^{\mathrm{c}} \\
& 3.1^{\mathrm{d}} \\
& 3.7^{\mathrm{d}} \\
& 2.7^{\mathrm{d}}\end{aligned}$ & $\begin{array}{r}>17.0^{\mathrm{a}} \\
>15.9^{\mathrm{b}} \\
>16.1^{\mathrm{b}} \\
\\
4.4^{\mathrm{d}} \\
\\
6.3^{\mathrm{c}} \\
\\
4.0^{\mathrm{d}}\end{array}$ & $\begin{aligned}> & 17.0^{\mathrm{a}} \\
> & 16.1^{\mathrm{ab}} \\
> & 16.4^{\mathrm{b}} \\
& 6.1^{\mathrm{d}} \\
& 7.1^{\mathrm{c}} \\
& 4.2^{\mathrm{d}}\end{aligned}$ & $\begin{array}{r}>17.0^{\mathrm{a}} \\
>16.5^{\mathrm{a}} \\
>17.0^{\mathrm{a}} \\
\\
8.2^{\mathrm{b}} \\
\\
8.0^{\mathrm{b}} \\
\\
6.0^{\mathrm{c}}\end{array}$ & $\begin{array}{r}>17.0^{\mathrm{a}} \\
>16.5^{\mathrm{a}} \\
>17.0^{\mathrm{a}} \\
\\
9.3^{\mathrm{b}} \\
8.0^{\mathrm{d}} \\
\\
8.6^{\mathrm{c}}\end{array}$ \\
\hline$F$-test & $* *$ & $* *$ & $* *$ & $* *$ & $* *$ & $* *$ \\
\hline
\end{tabular}

Means within columns not sharing the same letter are significantly different at $P=0.01(\mathrm{DMRT})$ and ${ }^{* *}=\operatorname{significant}$ at $P=0.01$

give a volume $0.9 \mathrm{ml}$ after the addition of the $\mathrm{HgCl}_{2}$. The ethylene production was measured after the addition of the bleach base solution as described above. The conversion efficiency of freshly made floral extracts was found to be close to $100 \%$. ACC content was expressed as nmol ACC formed per g FW.

\section{IAA in pollinia}

IAA in pollinia was extracted and analyzed following the method of Abdel-Rahman et al. (1975). Three hundred $\mathrm{mg}$ of pollinia were extracted in $15 \mathrm{ml}$ cold methanol (95\%). The residue after extraction and separation of the ethyl acetate was evaporated and the residue dissolved in $1 \mathrm{ml}$ of $100 \%$ methanol and the IAA in the purified extract was determined using high pressure liquid chromatography (HPLC).

\section{High-performance liquid chromatographic analysis of indole-acetic acid}

One $\mathrm{ml}$ of pollen extract was filtered through a $\mathrm{Ny}$ lon Acrodisc $13(0.45 \mu \mathrm{m})$. The HPLC analyses were carried out using a Shimadzu class LC-VP HPLC system with LC-VP software, a pump (LC-10AD VP) and a UV detector (SPD-10A VP) (Shimadzu, Kyoto, Japan). The separation was carried out on a Alltima C18 column $5 \mu$ $(250 \times 4.6 \mathrm{~mm})$ Lot No. 2672 (Alltech, USA) with guard column (CLC-ODS(4), $10 \times 4 \mathrm{~mm}$ I.D.), using 30\% methanol and $0.8 \%$ acetic acid as the mobile phase at a flow rate $1.5 \mathrm{ml} / \mathrm{min}$ and monitored at $280 \mathrm{~nm}$. The retention time for IAA peak was $12.8 \mathrm{~min}$.

\section{Results}

\section{Time of senescence following pollination with different pollinia}

Dendrobium 'Miss Teen' flowers were either self-pollinated or pollinated with pollinia from four other cultivars and non-pollinated flowers served as the control. Two types of behaviour were observed. Early symptoms of senescence (epinasty, lip yellowing, venation and water soaking) and early ovary growth were recorded

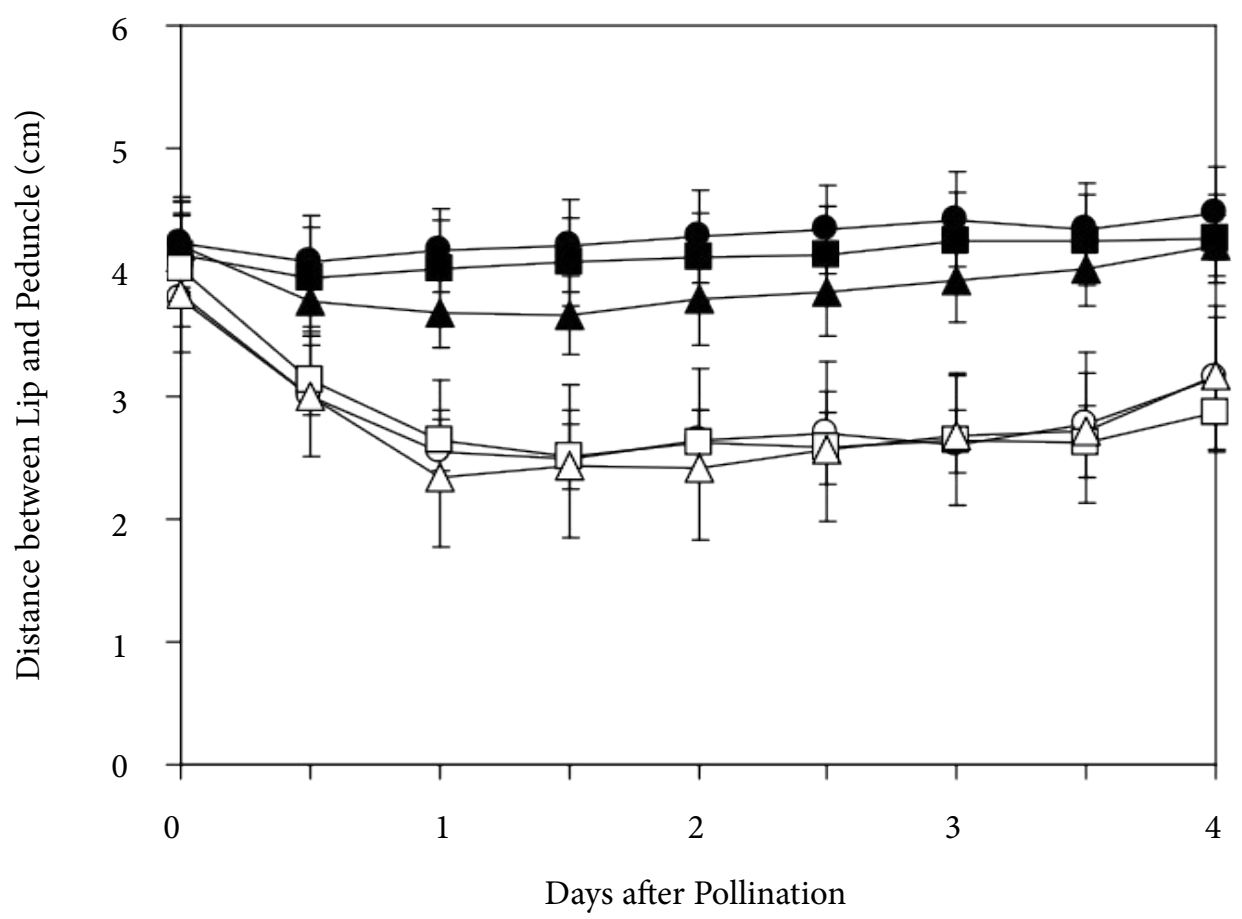

Fig. 1 Changes in distance between lip and peduncle of non-pollinated Dendrobium Miss Teen' flowers $(\bullet)$ and those pollinated with pollinia from

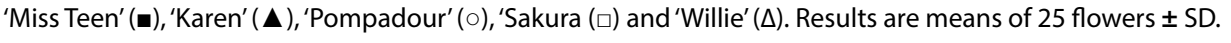




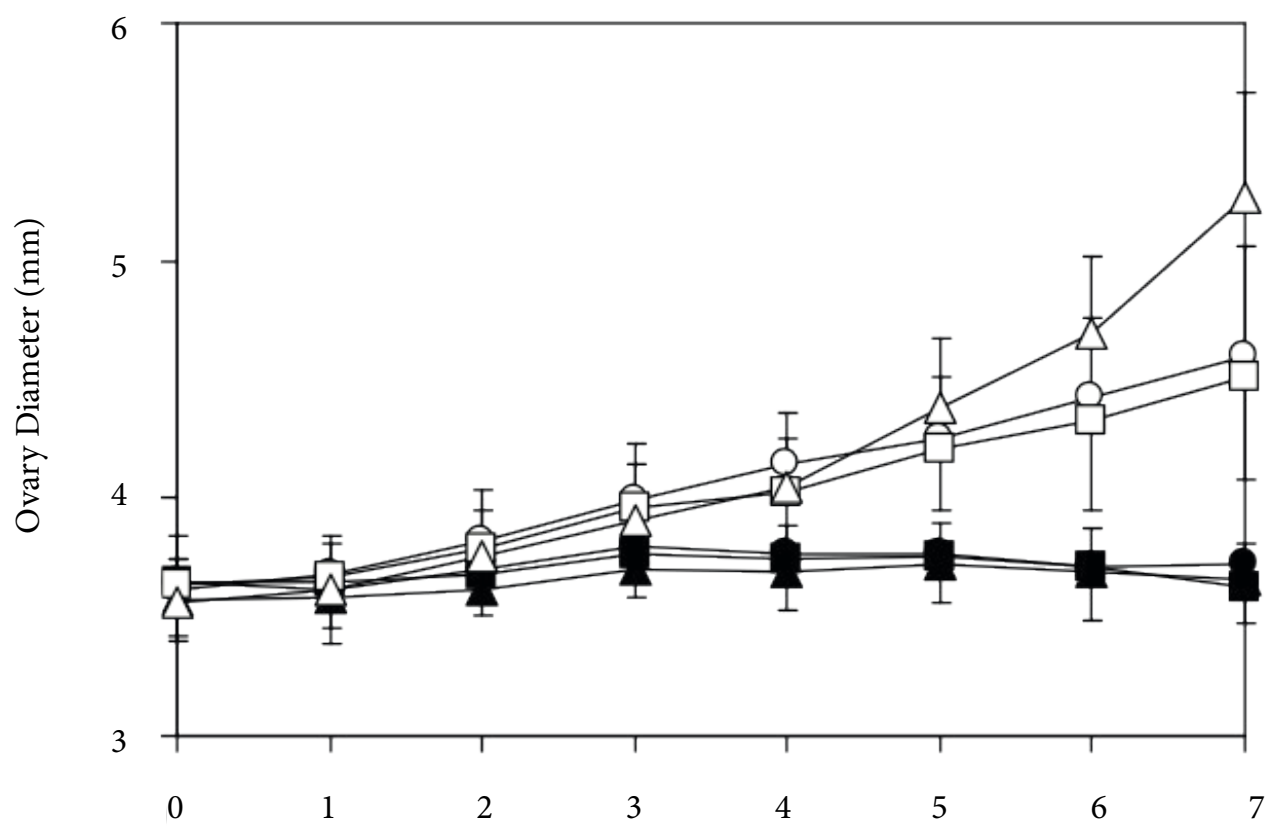

Days after Pollination

Fig. 2 Ovary growth of non-pollinated Dendrobium 'Miss Teen' flowers ( $\bullet$ ) and those pollinated with pollinia from 'Miss Teen' ( $\boldsymbol{\square})$, 'Karen' ( $\boldsymbol{\Delta}$ ), 'Pompadour' ( $\square)$, 'Sakura ( () and 'Willie' $(\Delta)$. Results are means of 25 flowers \pm SD.

when Dendrobium 'Miss Teen' flowers were cross-pollinated with compatible pollinia from 'Pompadour', 'Sakura' and 'Willie' cultivars (Table 1). The second type of behaviour in which there was delayed senescence and ovary growth was recorded after self-pollination of 'Miss Teen' flowers or after cross-pollination of 'Miss Teen' flowers with incompatible 'Karen' pollinia. The delay in senescence was similar to that recorded for non-pollinated flowers. The senescence of flowers was expressed in terms of several symptoms that developed sequentially. Flower epinasty was the earliest of the senescence symptoms and occurred within 1-2 days in the case of compatible pollination. Drooping developed 2-3 days after pollination (DAP) followed by colour fading, yellowing of lip and water soaking (data not shown). Lip yellowing, fading and browning following incompatible pollination were the same as that recorded for non-pollinated control flowers but epinasty, droop-

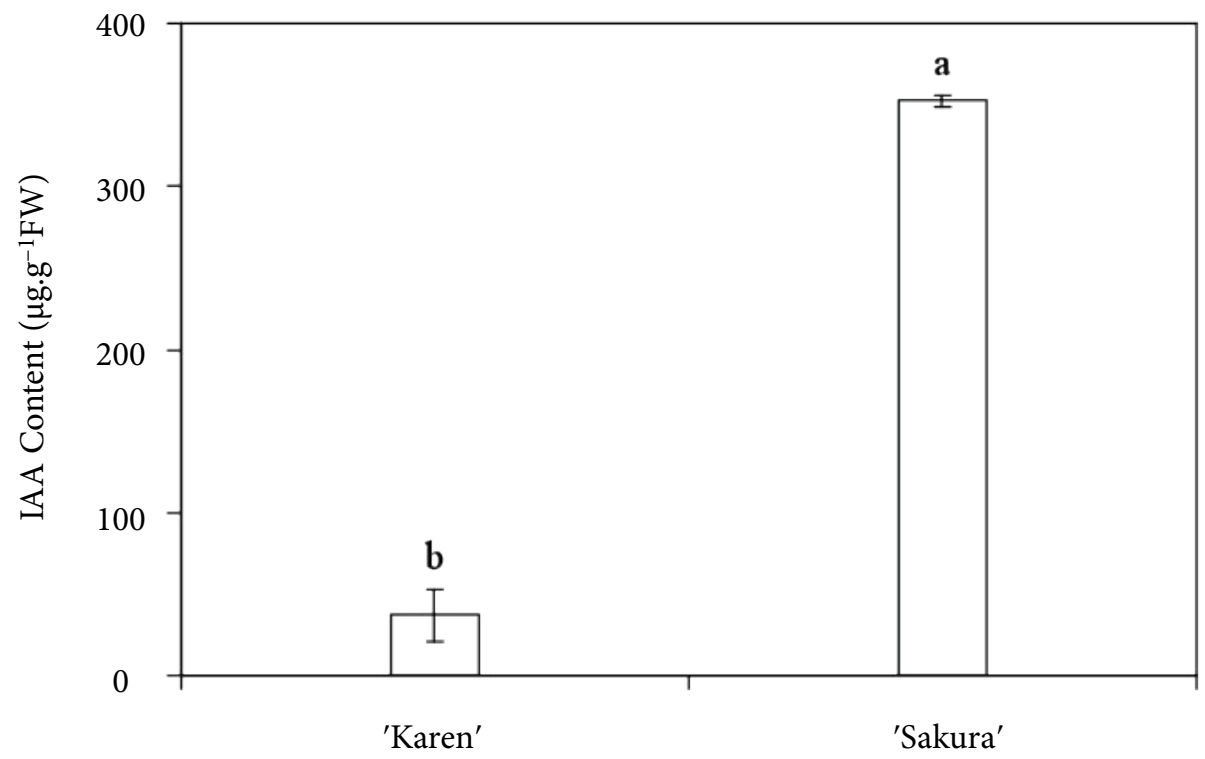

Fig. 3 Content of IAA in pollinia from Dendrobium 'Karen' and 'Sakura'. Results are means of 3 replicates \pm SD. Different letters indicate significant differences at $p \leq 0.05$ based on $t$-tests. 


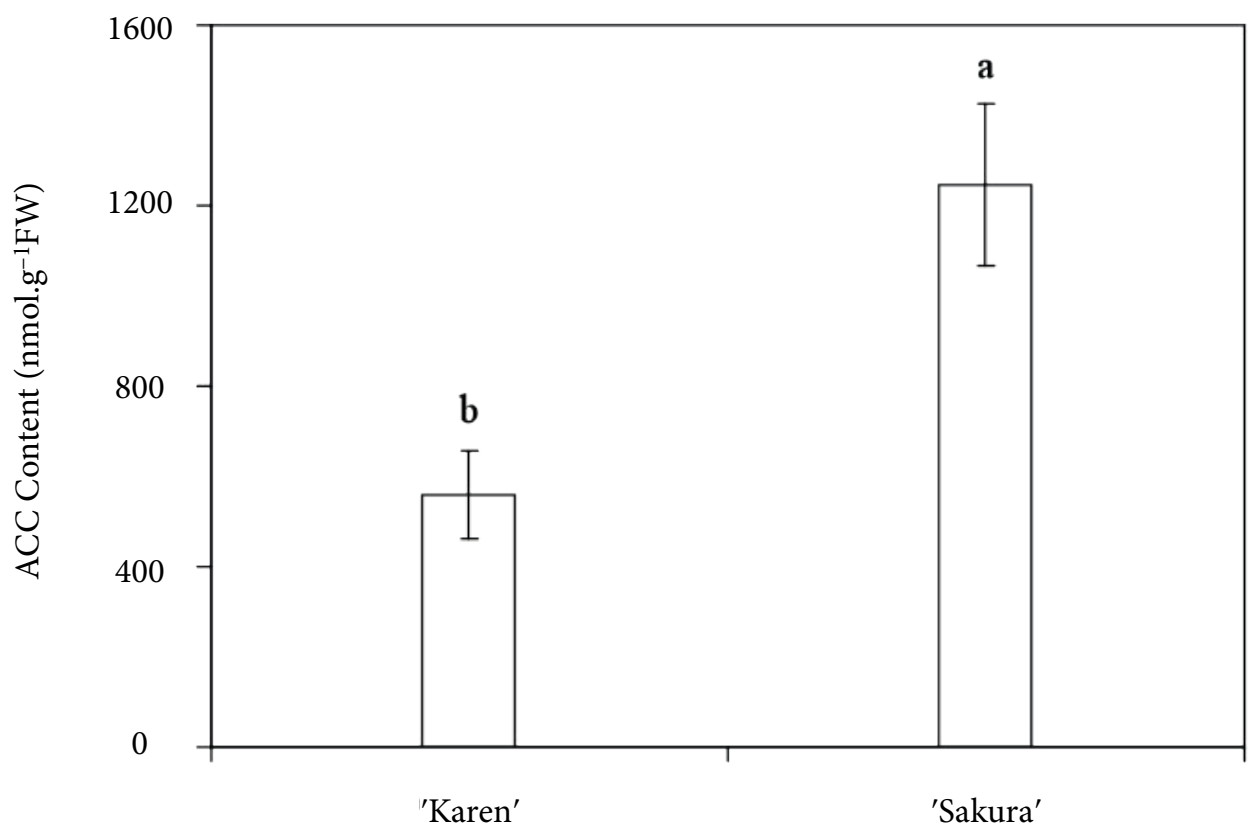

Fig. 4 Content of ACC in pollinia from Dendrobium 'Karen' and 'Sakura'. Results are means of 3 replicates \pm SD. Different letters indicate significant differences at $p \leq 0.05$ based on $t$-tests.

ing and changes in the venation occurred slightly faster (Table 1).

When pollinia of 'Pompadour', 'Sakura', and 'Willie' were placed on the stigma of 'Miss Teen' the column (tissue around the stigma) was observed to rapidly swell within 1 DAP. The colour of the pedicel changed from white to green accompanied by the enlargement of the proximal end of the pedicel. These changes were not record- ed for non-pollinated flowers, self-pollinated 'Miss Teen' flowers or those pollinated with pollinia from 'Karen'.

\section{Effects of pollination on the distance between lip and peduncle}

Within 12 hours of pollination (HAP) the distance between lip and peduncle changed. The distance between the lip and peduncle of flowers of 'Miss Teen' pollinat-

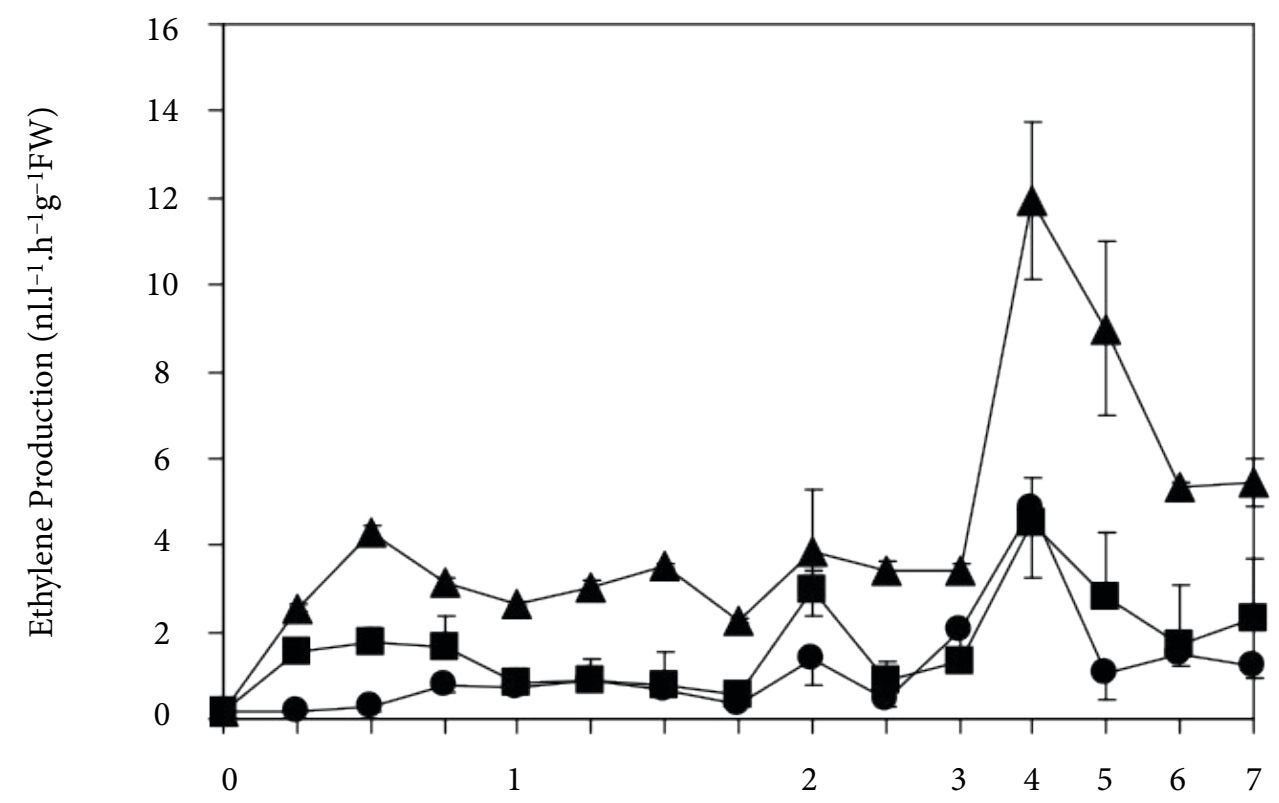

Days after Pollination

Fig. 5 Ethylene production by non-pollinated flowers of Dendrobium 'Miss Teen' $(\bullet)$ and those compatibly pollinated ( $\times$ 'Sakura') ( $\boldsymbol{\Delta}$ ) and incompatibly pollinated ( $\times^{\prime}$ Karen') $(\square)$. Results are means of 10 replicates \pm SD. 


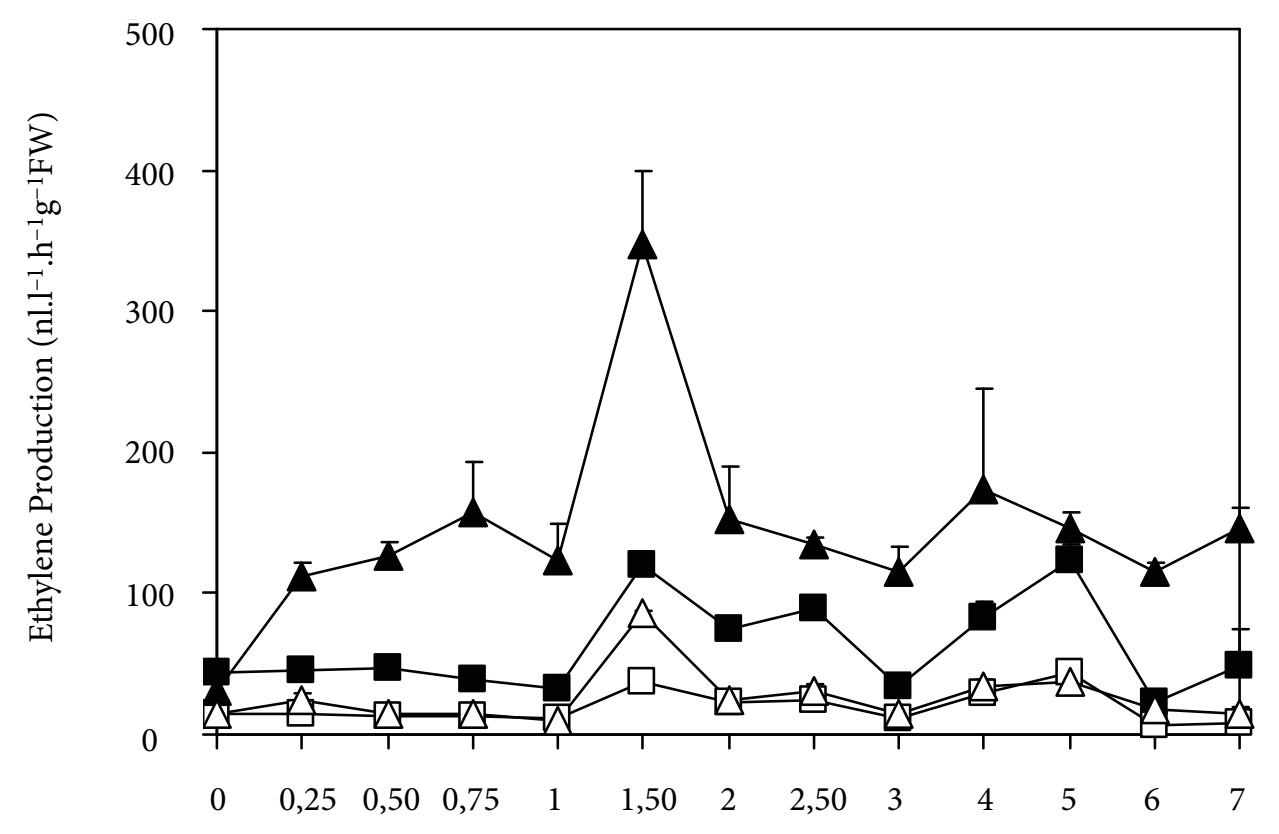

Days after Pollination

Fig. 6 Ethylene production by the column plus pedicel of non-pollinated ( $\square$ ), petal, sepal plus lip of non-pollinated ( $\square$ ), column plus pedicel of compatibly pollinated $(\mathbf{\Delta})$ and petal, sepal plus lip of compatibly pollinated $(\Delta)$ flowers of Dendrobium 'Miss Teen'. Results are means of 5 replicates \pm S.

ed with compatible pollinia ('Pompadour', 'Sakura' and 'Willie') rapidly decreased, which resulted in the epinasty of the flowers (Fig. 1). The distance between lip and peduncle in the case of incompatible pollination was only slightly less but epinasty of the flowers did not occur. The distance between lip and peduncle of non-pollinated flower remained unchanged (Fig. 2).

\section{Ovary diameter}

The diameter of the ovary of flowers of 'Miss Teen' either non-pollinated or self-pollinated or pollinated with pollinia from 'Karen' remained unchanged over the experimental period. In contrast, compatible pollination resulted in a steady increase in the diameter of the ovary over the 7-day period of the experiment (Fig. 2).

\section{Quantity of IAA and ACC in pollinia}

The incompatible pollinia of 'Karen' contained low amounts of IAA and ACC, while the compatible pollinia of 'Sakura' contained relatively high amounts of both IAA and ACC (Figs. 3 and 4, respectively).

\section{Ethylene production}

Compatibly pollinated flowers ( $\times$ 'Sakura') produced more ethylene than incompatibly pollinated flowers ( $\times$ 'Karen'). The ethylene production of compatibly pollinated flowers increased and peaked within 12 HAP and remained high and peaked again on day 4, whereas non-pollinated flowers produced very little ethylene (Fig. 5). The high levels of ethylene induced by pollination were produced by the column plus pedicel and the petal, sepal plus lip produced very little ethylene (Fig. 6).

\section{Discussion}

Pollination with pollinia from Dendrobium 'Sakura' stimulated a high level of ethylene production and subsequently the early senescence of the perianth of the flowers of Dendrobium. The results using 'Miss Teen' are similar to those for Dendrobium 'Pompadour' (Ketsa and Rugkong 2000), Phalaenopsis (Zhang and O’Neill 1993), petunia (Singh et al. 1992) and tobacco (Hill et al. 1987). Following pollination by pollinia from cultivar 'Sakura' the ovary grew considerably but there was little or no effect after pollination with pollinia from Dendrobium ' $\mathrm{Ka}$ ren'. In this study, ethylene production following compatible and incompatible pollination was clearly different. Ethylene production and ovary growth increased after pollination with compatible pollinia.

Pollinia of Dendrobium are known to be rich in auxin (IAA) and ACC (Arditti 1979; Stead 1992). However, the concentrations of IAA and ACC in 'Karen' pollinia was low and in 'Sakura' pollinia relatively high. The variation in the IAA and ACC contents of pollinia, however, depends on the genetic background, may also account for the difference in the compatible and incompatible pollinia. Pollinia of 'Sakura', which were compatible, contained high levels of IAA and ACC, while those of 'Karen', which were incompatible, contained low amounts of IAA and ACC. Baker et al. (1997) report that in Theobroma cacao L., IAA concentrations in flowers pollinated with compatible pollinia increase but remain stable in those pollinated with incompatible pollinia.

The bursts of ethylene production, ovary growth and premature senescence were triggered by cross-pollina- 
tion with pollinia from 'Sakura' but not by cross-pollination with incompatible pollinia from 'Karen'. The major factor determining why cross pollination with compatible pollinia induces high levels of ACC and IAA in the pollinia, which seems to stimulate ovary development, is apparently related to pollen germination (Singh et al. 1992; Luangsuwalai et al. 2008). It is unknown whether premature senescence is also directly induced by these two chemicals, which may act directly on the petals or via their effect on the ovary. A second part of the causal chain may be the differences in pollen germination and pollen tube growth. Both seem to require ethylene because application of AOA and/ or 1-MCP to the stigma before compatible cross-pollination reduces pollinia tube and ovary growth (Luangsuwalai et al. 2008). It is also unknown to what extent they are required for the induction of premature senescence. In contrast, in Phalaenopsis the pollination-induced senescence syndrome is not associated with pollen germination as the pollen starts to germinate 7 days after pollination, which is long after the petals have completely wilted (Zhang and O'Neill 1993). In tomato, ethylene promotes pollen germination and pollen tube growth (McLeod 1975) and increases germination and pollen growth in pear (Search and Stanley 1970) and peach (Buchanan and Biggs 1969). De Martinis et al. (2002) have demonstrated that the production of ethylene by flowers of tobacco upon pollination is a direct response to pollen tube growth.

Using the compatible pollinia from Dendrobium 'Sakura' and the incompatible pollinia from Dendrobium 'Karen' for pollination revealed that flowers pollinated with compatible pollinia produced a burst of ethylene. Pollination with compatible pollinia not only induce an increase in ethylene production but also an increase in sensitivity to ethylene (Porat et al. 1994). Flowers pollinated with incompatible pollinia produced low levels of ethylene. The pattern in the ethylene production by flowers pollinated with compatible and incompatible pollinia, and non-pollinated flowers were similar to that reported for petunia (Singh et al. 1992). Incompatible pollination did not stimulate early senescence as fast as compatible pollination (Table 1). In compatible pollination, it is possible that the stigma perceived the primary pollination signal from pollinia and then transmitted and amplified this primary signal, which coordinates inter-organ post-pollination responses (O’Neill 1997). Incompatible pollination slightly affected ethylene production, which then decreased and remained low, similar to that recorded in non-pollinated flowers. It seems that the signal from incompatible pollination was not strong enough to elicit early petal senescence, such as lip yellowing and fading. The results reported here raise several interesting questions about the role of pollination-induced ethylene. Ketsa et al. (2001) report that Dendrobium flowers pollinated with pollen from plants other than Dendrobium, produced levels of ethylene similar to flowers pollinated by compatible pollen, but no growth in the ovary. Therefore, pollination-induced ethylene production alone does not promote pollen tube and ovary growth, which may be due to other pollination-induced factors (Singh et al. 1992).

It is concluded that Dendrobium flowers can be pollinated by both compatible and incompatible pollinia. Pollination by compatible pollinia induces early perianth senescence and ovary growth but pollination by incompatible pollinia does not result in early senescence of the perianth or ovary growth. Compatible pollinia contain greater amounts of auxin and ACC, and induce a greater production of ethylene than incompatible pollinia.

\section{Acknowledgements}

The research was financially supported by the Thailand Research Fund (TRF), the Commission on Higher Education (CHE), Ministry of Education and the Kasetsart University Research and Development Institute (KURDI).

\section{REFERENCES}

Abdel-Rahman M, Thomas TH, Doss GJ, Howell L (1975) Changes in endogenous plant hormones in cherry tomato fruits during development and maturation. Physiol Plant 34: 39-43.

Aggarwal S, Nirmala C, Beri S, Rastogi S, Adholeya A (2012) In vitro symbiotic seed germination and molecular characterization of associated endophytic fungi in a commercially important and endangered Indian orchid Vanda coerulea Griff. Ex Lindl. Eur J Environ Sci 2: 33-42.

Arditti J (1979) Aspects of the physiology of orchids. Adv Bot Res 7: 421-55.

Baker RP, Hasenstein KH, Zavada MS (1997) Hormonal changes after compatible and incompatible pollination in Theobroma cacao L. Hort Sci 32: 1231-1234.

Buchanan DW, Biggs RH (1969) Peach fruit abscission and pollen germination as influenced by ethylene and 2-chloroethanephosphonic acid. J Amer Soc Hort Sci 94: 327-320.

Cevdet G, Sebnem E (2012) Seed germination and develoment of Serapias vomeracea (Burm.fil.) Briq. spp. orientalis Greuter in tissue culture. Res J Biotechnol 7: 4-8.

Damon A, Hernández-Ramírez F, Riggi L, Verspoor R, Bertolini V, Lennartz-Walker M, Wiles A, Burns A (2012) Pollination of euglossinophylic epiphytic orchids in agroecosystems and forest fragments in southeast Mexico. Eur J Environ Sci 2: 5-14.

De Martinis D, Cotti G, Te Lintel Hekkert S, Harren FJM, Mariani C (2002) Ethylene response to pollen-tube growth in the Nicotiana tabacum flower. Planta 214: 806-812.

Halevy AH (1995a) The role of sensitivity to ethylene in pollination-induced corolla senescence syndrome. Acta Hort 405: 210-215.

Halevy AH (1995b) The role of sensitivity to ethylene in pollination induced corolla senescence syndrome. Proceedings of Australian Postharvest Horticulture Conference: Science and Technology for the Fresh Food Revolution Melbourne, Australia. pp 75-80.

Halevy AH, Whitehead CS, Kofranek AM (1984) Does pollination induce corolla abscission of cyclamen flowers by promoting ethylene production? Plant Physiol 75: 1090-1093. 
Have A, Woltering EJ (1997) Ethylene biosynthetic genes are differentially expressed during carnation (Dianthus caryophyllus L.) flower senescence. Plant Mol Biol 34: 89-97.

Herrero M, Dickinson HG (1979) Pollen-pistil incompatibility in Petunia hybrida: change in the pistil following compatible and incompatible intraspecific crosses. J Cell Sci 36: 1-18.

Herrero M, Dickinson HG (1980) Pollen tube growth following compatible and incompatible intraspecific pollinations in Petunia hybrida. Planta 148: 217-221.

Hill SE, Stead AD, Nichols R (1987) Pollination-induced ethylene and production of 1-aminocyclopropane-1-carboxylic acid by pollen of Nicotiana tabacum cv White Burley. J Plant Growth Regul 6: 1-13.

Hoffman NE, Yang SF (1982) Enhancement of wound-induced ethylene synthesis by ethylene in preclimacteric cantaloupe. Plant Physiol 69: 317-322.

Ketsa S, Rugkong A (1999) Senescence of Dendrobium 'Pompadour' flowers following pollination. J Hort Sci Biotech 74: 608-613.

Ketsa S, Rugkong A (2000) Ethylene production, senescence and ethylene sensitivity of Dendrobium 'Pompadour' flowers following pollination. J Hort Sci Biotech 75: 149-153.

Ketsa S, Bunya-Atichart K, van Doorn WG (2001) Ethylene production and post-pollination in Dendrobium flowers treated with foreign pollen. Austral J Plant Physiol 28: 409-415.

Lizada MCC, Yang SF (1979) A simple and sensitive assay for 1-aminocyclopropane-1-carboxylic acid. Ann Biochem 100: 140-145.

Luangsuwala K, Ketsa S, Wisutiamonkul A, van Doorn WG (2008) Lack of visible post-pollination effects in pollen grains of two Dendrobium cultivars: relationship with pollinia ACC, pollen germination, and pollen tube growth. Funct Plant Biol 35: 152-158.

McCubbin AG, Kao T (2000) Molecular recognition and response in pollen and pistil interactions. Ann Rev Cell Dev Biol 16: 333-64.

McLeod KA (1975) The control of growth of tomato pollen. Ann Bot 39: 591-596.
O’Neill SD (1997) Pollination regulation of flower development. Ann Rev Plant Physiol and Plant Mol Biol 48: 547-74.

Porat R, Borochov A, Halevy AH (1994) Pollination induced senescence in Phalaenopsis petals. Relationship of ethylene sensitivity to activity of GTP-binding proteins and protein phosphorylation. Physiol Plant 90: 679-684.

Porat R, Halevy AH, Serek HM, Borochov A (1995) An increase in ethylene sensitivity following pollination is the initial event triggering an increase in ethylene production and enhanced senescence of Phalaenopsis orchid flowers. Physiol Plant 93: 778-784.

Porat R, Nadeau JA, Kirby JA, Sutter EG, O’Neill SD (1998) Characterization of the primary pollen signal in the post-pollination syndrome of Phalaenopsis flowers. J Plant Growth Regul 24: 109-117.

Search RW, Stanley RG (1970) Stimulation of pollen growth in vitro by ethylene. Phyton 27: 35-39.

Singh A, Evensen KB, Kao T (1992) Ethylene synthesis and floral senescence following compatible and incompatible pollination in Petunia inflata. Plant Physiol 99: 38-45.

Stead AD (1992) Pollination-induced flower senescence: a review. Plant Growth Regul 11: 13-20.

Taiz L, Zeiger E (1998) Plant Physiology. Sinauer Associates Publishers, Sunderland, Massachusetts.

Woltering EJ, Somhorst D, van der Veer P (1995) The role of ethylene in inter-organ signaling during flower senescence. Plant Physiol 109: 1219-1225.

Woodson WR, Lawton KA (1988) Ethylene - induced gene expression in carnation petals. Relationship to autocatalytic ethylene production and senescence. Plant Physiol 87: 498-503.

Xu Y, Hanson MR (2000) Program cell death during pollination-induced petal senescence in petunia. Plant Physiol 122: 1323-1333.

Yang SF, Hoffman NE (1984) Ethylene biosynthesis and its regulation in higher plants. Ann Rev Plant Physiol 35: 155-189.

Zhang XS, O’Neill SD (1993) Ovary and gametophytic development are coordinately regulated by auxin and ethylene following pollination. Plant Cell 5: 403-418. 